\title{
Oportunidades e Entraves Para a Proteção por Indicação de Procedência para os Biscoitos Artesanais de Vitória da Conquista-BA
}

\author{
Núbia Moura Ribeiro \\ Instituto Federal da Bahia - Salvador - BA - Brasil \\ ORCID: https://orcid.org/0000-0002-0468-9760 \\ Marta Aparecida Rodrigues de Oliveira \\ Instituto Federal da Bahia - Salvador - BA - Brasil \\ ORCID: https://orcid.org/0000-0002-3580-1268 \\ Marcelo Santana Silva \\ Instituto Federal da Bahia - Salvador - BA - Brasil \\ ORCID: https://orcid.org/0000-0002-6556-9041
}

\begin{abstract}
Resumo
Os biscoitos artesanais produzidos na região de Vitória da Conquista, na Bahia, são produtos regionais que demonstram notoriedade e podem ser passíveis de proteção por Indicação Geográfica. O produto é fruto de tradição local, cujo saber fazer vem sendo passado de geração em geração há aproximadamente um século. Desde 2005 este produto é visto pelo sistema de governança do Serviço Brasileiro de Apoio às Micro e Pequenas Empresas (SEBRAE) como oportunidade para criação de negócios e promoção da região. $O$ presente trabalho tem como objetivo analisar os principais entraves e oportunidades para 0 registro de proteção por Indicação de Procedência (IP) para os biscoitos de Vitória da Conquista, bem como sugerir estratégias de fomento. Para tanto, utilizou-se como metodologia a abordagem qualitativa, descritiva, de natureza exploratória, com pesquisa documental e análise de conteúdo, além de visitas técnicas aos produtores e ao SEBRAE. A metodologia utilizada para embasar este estudo foi a do círculo virtuoso de qualidade ligado à origem desenvolvido pela Organização das Nações Unidas para Alimentação e Agricultura. Os resultados demonstraram que os biscoitos de Vitória da Conquista possuem potencial para o registro de Indicação de Procedência e oferece inúmeros benefícios e oportunidades para a região. Todavia, foi detectado vários entraves para o seu fomento, com destaque para a falta de uma entidade que agrupe os produtores e comerciantes e a falta de políticas públicas voltadas específicas para IG, dentre outras. Foram sugeridas estratégias que possam contribuir para a promoção e para seu desenvolvimento local.

Palavras-chave: Indicação Geográfica. Indicação de Procedência. Biscoitos de Vitória da Conquista. Desenvolvimento Local.
\end{abstract}


Oportunidades e Entraves Para a Proteção por Indicação de Procedência para os Biscoitos Artesanais de Vitória da Conquista-BA

\title{
Opportunities and Constraints for Protection by Procedure Indication for Conquista Victory-BA Handmade Biscuits
}

\begin{abstract}
The cookies produced in the region of Vitória da Conquista, in Bahia, is one of the regional products that shows notoriety and may be subject to protection by Geographical Indication. The product is the fruit of local tradition, whose know-how has been passed on from generation to generation for approximately a century. This product has been seen since 2005 by the governance system of the Brazilian Micro and Small Business Support Service (SEBRAE) as an opportunity for business creation and promotion in the region. The present work aims to analyze the main obstacles and opportunities for the registration of protection by Indication of Origin (IP) for the cookies from Vitória da Conquista, as well as to suggest promotion strategies. To this end, a qualitative, descriptive, exploratory approach was used as a methodology, with documentary research and content analysis, in addition to technical visits to biscuit producers and the Brazilian Micro and Small Business Support Service. The methodology used to support this study was that of the virtuous circle of quality linked to the origin developed by the United Nations Food and Agriculture Organization. The results showed that the cookies from Vitória da Conquista have the potential to register the Indication of Origin and offer numerous benefits and opportunities for the region. However, several obstacles to its promotion were detected, with emphasis on: the lack of an entity that groups producers and traders and lack of specific public policies for $\mathrm{Gl}$, among others. Strategies have been suggested that can contribute to the promotion and its development.
\end{abstract}

Keywords: Geographical Indication. Indication of Origin. Cookies of Vitoria da Conquista. Local Development.

\section{Oportunidades y barreras para la protección por indicación de origen de las galletas artesanales de Vitória da Conquista-BA}

\section{Resumen}

Las galletas hechas a mano producidas en la región de Vitória da Conquista, en Bahía, son productos regionales que demuestran notoriedad y pueden estar sujetas a protección por indicación geográfica. El producto es fruto de la tradición local, cuyo conocimiento se ha transmitido de generación en generación durante aproximadamente un siglo. Desde 2005, este producto ha sido visto por el sistema de gobierno del Servicio Brasileño de Apoyo a las Micro y Pequeñas Empresas (SEBRAE) como una oportunidad para crear negocios y promover la región. El presente trabajo tiene como objetivo analizar los principales obstáculos y oportunidades para el registro de protección por Indicación de Origen (IP) para las cookies de Vitória da Conquista, así como sugerir estrategias de promoción. Para ello, se utilizó un enfoque cualitativo, descriptivo, exploratorio como metodología, con investigación documental y análisis de contenido, además de visitas técnicas a productores y SEBRAE. La metodología utilizada para apoyar este estudio fue la del círculo virtuoso de calidad vinculado al origen desarrollado por la Organización de las Naciones Unidas para la Alimentación y la Agricultura. Los resultados mostraron que las cookies de Vitória da Conquista tienen el potencial de registrar la Indicación de Origen y ofrecen numerosos beneficios y oportunidades para la región. Sin embargo, se detectaron varios obstáculos para su promoción, con énfasis en la falta de una entidad que reúna a productores y comerciantes y la falta de políticas públicas dirigidas específicamente a IG, entre otros. Se han sugerido estrategias que pueden contribuir a la promoción y el desarrollo local.

Palabras clave: indicación geográfica. Indicación de origen. Galletas de Vitória da Conquista. Desarrollo local 


\section{Introdução}

A Indicação Geográfica (IG) é um tipo de proteção no ramo da propriedade industrial usada para atestar a origem de um produto ou serviço, quando o local de produção ou prestação do serviço ficou conhecido por sua notoriedade, ou então, quando algum atributo ou qualidade desse produto ou serviço é devido ao local geográfico como clima e solo (INPI, 2019a).

O Brasil possui grande potencial para o registro de indicações geográficas, devido à quantidade de regiões que são reconhecidas pelos seus produtos e/ou serviços com condições de se tornarem centros de produção de qualidade (CONEJERO e CÉSAR, 2017; MEDEIROS et al., 2016; WILKINSON et al., 2017; PEREIRA et al., 2018; MARQUES et al., 2019).

Atualmente a lei brasileira vigente para IG é a Lei $n^{\circ} 9.279$ de 14/05/1996 (conhecida como Lei da Propriedade Industrial, LPI), (BRASIL, 1996), que estabelece as regras gerais para registro de IG. Em termos de normativas, há também a Instrução Normativa PR nº 095/2018, de 28/12/2018 (BRASIL, 2018), que determina as condições para registro de IG. Está em vigência também a Resolução PR n²33, de 18/01/2019 (INPI 2019b), que criou o módulo de petição eletrônico para IG. Portanto, as solicitações de registro de IG devem se guiar por esses três dispositivos legais.

A LPI estabelece, entre outras, as regras para o registro de Indicação Geográfica (IG) que é constituída pela Indicação de Procedência (IP) e pela Denominação de Origem (DO) (BRASIL, 1996). O registro de Indicação de Procedência (IP) requer apresentação de evidências que comprovem que o nome geográfico se tornou conhecido como local de extração e/ou fabricação do produto ou prestação do serviço, ou seja, para o registro de uma IP é necessário, dentre outros itens, ser atendido o critério de notoriedade do produto ou serviço (INPI, 2019a).

Um dos produtos regionais que demonstra notoriedade e que, portanto, pode ser passível de proteção por IG, são os biscoitos produzidos na região de Vitória da Conquista, na Bahia, Brasil, que desde 2005 é foco de pesquisa e governança do Serviço Brasileiro de Apoio às Micro e Pequenas Empresas (SEBRAE) como oportunidade para criação de negócios e promoção da região (SEBRAE, 2008). O SEBRAE também realizou, em 2019, um estudo intitulado: "Diagnóstico de Potencial para Indicação Geográfica 'Vitória da Conquista' para Biscoitos”, com o objetivo de identificar o potencial de Indicação Geográfica para os municípios Vitória da Conquista e Condeúba, produtores de biscoitos (SEBRAE, 2019).

O trabalho aqui apresentado enfoca os biscoitos produzidos em Vitória da Conquista, e entende que trata de um produto produzido de forma artesanal e, portanto, preparado priorizando o uso das mãos no modo de fazer, com mecanização parcial, com a presença humana em todas as etapas de produção, utilizando ingredientes de qualidade e com uso limitado de conservantes, corantes ou outros aditivos químicos que são usados nos biscoitos produzidos de forma industrial. Esta pesquisa objetivou analisar os principais entraves e oportunidades para o registro de proteção por Indicação de Procedência (IP), uma das modalidades de IG, para os biscoitos artesanais de Vitória da Conquista, Bahia, Brasil, bem como sugerir estratégias para fomentar a produção do produto na região. 
A estrutura do artigo é composta de sete seções. Além da presente introdução, na seção 2 apresenta um levantamento das indicações geográficas no Brasil e os seus benefícios e dificuldades, na seção 3 realiza-se os matérias e métodos, na seção 4 relata os dados no município e a produção de biscoitos artesanais, no item 6 onde são apresentados os entraves e oportunidades, no item 6 são sugeridas as estratégias e, por fim os comentários finais.

\section{Indicações Geográficas no Brasil}

Atualmente a lei brasileira vigente para IG é a Lei $n^{\circ}$ 9.279, de 14/05/1996 (BRASIL, 1996), que estabelece as regras gerais para registro de IG. Em termos de normativas, há também a Instrução Normativa 095, de 28 de dezembro de 2018 que estabelece atualmente as condições para o registro das Indicações Geográficas no Brasil (BRASIL, 2018). De acordo com essa atual normativa, a Indicação de Procedência e a Denominação de Origem são definidas conforme a seguir:

$\S 1^{\circ}$ Considera-se Indicação de Procedência o nome geográfico de país,
cidade, região ou localidade de seu território, que se tenha tornado
conhecido como centro de extração, produção ou fabricação de
determinado produto ou de prestação de determinado serviço.
$\S 2^{\circ}$ Considera-se Denominação de Origem o nome geográfico de país,
cidade, região ou localidade de seu território, que designe produto ou
serviço cujas qualidades ou características se devam exclusiva ou
essencialmente ao meio geográfico, incluídos fatores naturais e humanos.
$\$ 3^{\circ}$ Nome geográfico ou seu gentílico, que poderá vir acompanhado de
nome do produto ou do serviço, é o nome usado comumente para se
referir a um lugar em particular, a uma feição ou a uma área com
identidade reconhecida na superfície terrestre (BRASIL, 2018 a, sem
paginação).

O registro de Indicação de Procedência (IP) requer apresentação de evidências que comprovem que o nome geográfico se tornou conhecido como local de extração e/ou fabricação do produto ou prestação do serviço, ou seja, para o registro de uma IP é necessário, dentre outros itens, ser atendido o critério de notoriedade do produto ou serviço (INPI, 2019a).

Os depósitos de pedidos para registros de Indicações Geográficas começaram a ocorrer no Brasil após a publicação da LPI em 1996 quando passaram a vigorar as regras para IG no país. Os dados correspondem ao andamento dos depósitos de indicações geográficas submetidos ao INPI a partir de agosto de 1997 até março de 2020, publicados na Revista da Propriedade Industrial (RPI) n 2567 de 17/03/20 (INPI, 2020b).

O Gráfico 1 demonstra a evolução dos depósitos de IG no Brasil solicitados por residentes e por não residentes no país nos anos de 1997 a 2020, totalizando 143 depósitos até março de 2020, discriminando os pedidos de registro de Indicações de Procedência (IP) e de Denominações de Origem (DO). A maioria (61\%) dos pedidos são de IP, com um total de 88 depósitos de IP e 55 depósitos de DO. Os países que lideram os depósitos de IG no Brasil são a Itália, representando $45 \%$ dos pedidos, seguida por Portugal, com 17\%, e pela França, com 10\%. 
Gráfico 1. Evolução do número de depósitos de IG

$$
\square \mathrm{DO} \square \mathrm{IP}
$$

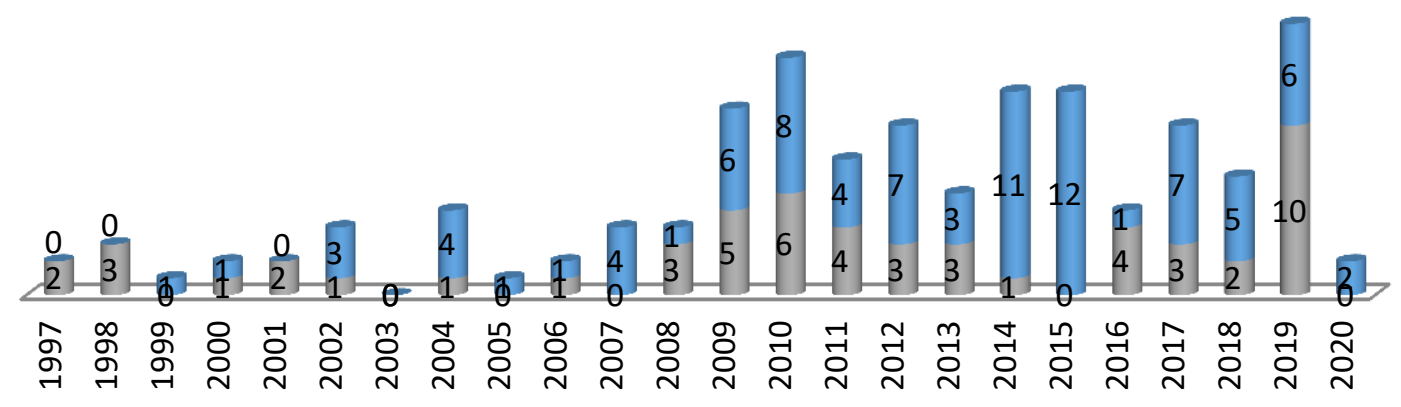

Fonte: Adaptado com base em INPI (2020). Acompanhamento de IGs/RPI n² 2567 de 17/03/20.

De acordo com os dados do INPI (2020), até março de 2020, o Brasil tem 55 IP concedidas a residentes no Brasil e 21 DO, sendo 12 Nacionais e 9 estrangeiras. Das Indicações de Procedência concedidas aos residentes, $46 \%$ é do ramo de alimentos; $30 \%$, de bebidas; $15 \%$, de artesanato e $9 \%$, outros tipos de produtos. Das DO concedidas aos residentes, $54 \%$ encontram-se no ramo de alimentos. As bebidas representam $18 \%$ e as pedras ornamentais representam $27 \%$ dessas concessões. Quanto as DO concedidas aos não residentes, 78\% são representadas por bebidas dos tipos vinho e destilado, e $22 \%$ por alimentos dos tipos queijo e presunto (INPI, 2020).

\subsection{Benefício e Dificuldades das Indicações Geográficas}

Uma IG possibilita benefícios econômicos, sociais e ambientais e agregam valor aos produtos tradicionais de diversas regiões do mundo (BARJOLLE et al., 2017; GOFFIC e ZAPPALAGLIO et al., 2017; AGOSTINO e TRIVIERI, 2014; CEI et al., 2018, MARQUES et al., 2019). Na esfera econômica proporciona agregação de valor ao produto que beneficia toda a cadeia produtiva, possibilita a manutenção ou aumento da oferta de emprego e dinamiza o desenvolvimento rural através do estímulo aos pequenos produtores. Na esfera social traz alguns benefícios à comunidade local como a preservação de tradições locais, fortalecimento de vínculos sociais entre os atores internos e externos, aumenta a autoestima em termos de identidade e estilo de vida com o reconhecimento do papel desempenhado por cada um no processo produtivo (VANDERCANDELAERE et al., 2010).

O registro de IG também pode se tornar um instrumento de proteção do patrimônio imaterial das regiões que possuem produtos diferenciados (DALLABRIDA, 2016; CONEJERO e CÉSAR, 2017; BELLETTI et al., 2017). Muitas vezes, as características locais dessa produção dão o diferencial do produto tornando-o único (PELLIN, 2019, p. 75). A tradição no saber fazer é o diferencial e por isso, mesmo que esse produto seja feito em outras regiões, não terá o mesmo sucesso. Dessa forma, a tradição local fica preservada através do registro da IG que 
assegurará que o produto será produzido conforme as regras estabelecidas (NIEDERLE at. al., 2016, PEREIRA et al., 2018).

Para Caldas et al. (2017, p.83-86), as IGs asseguram para grupos de produtores "a confiança, o aumento da autoestima, a uniformização da produção, a competitividade intra e inter-região produtora e a possibilidade desse território integrar-se no mundo da competitividade comercial". Porém, alertam os autores: a IG exige dos produtores o empenho em produzir com qualidade para ganhar a confiança do consumidor em relação à procedência do produto.

Um registro de IG estabelece regras coletivas que determinam a relação entre os fornecedores e produtores e isso possibilita ao consumidor saber a procedência da matéria-prima e do produto final (DA SILVA et al., 2017; WILKINSON et al., 2017; BELLETTI et al., 2017). Além disso, propicia inovações tecnológicas que melhoram a competitividade da cadeia produtiva valorizando o produto e aumentando a credibilidade do produtor (MEDEIROS et al., 2016; NIEDERLE at. al., 2017). Porém para que isso aconteça os produtores precisam cumprir essas regras (KEGEL e CARLS, 2015).

De acordo com Giesbrecht e Minas (2019) as IGs agregam valor ao produto através de aumento do preço, alcançam novos mercados (interno e externo), melhoram a qualidade da produção, adotam novas práticas, trazem inovação no controle e apresentação dos produtos. Porém foram constatadas também algumas dificuldades que precisam ser superadas, tais como:

[...] os pequenos produtores têm dificuldade em atender os requisitos da IG, principalmente no que diz respeito à legislação sanitária vigente e ao padrão específico de qualidade; as entidades gestoras das IGs têm dificuldade em controlar e rastrear a produção do conjunto de produtores que estão aptos a atender aos requisitos da IG; a governança coletiva dos ativos das IG precisa ser aprimorada, no sentido de gerar valor para os produtores; o conceito das IG precisa ser melhor conhecido e internalizado pelos consumidores; o acesso a mercados pelos produtos de IG precisa ser priorizado nas ações de estruturação da IG (GIESBRECHT; MINAS, 2019, p. 134).

De acordo com Schneider et al., (2017) o registro de IG em uma região também pode contribuir para o surgimento e/ou fortalecimento de serviços e atividades complementares à IG. Através da construção de uma cesta de serviços, é possível articular a IG com atividades complementares proporcionando surgimento de atividades turísticas, eventos culturais e gastronômicos, hotéis, pousadas, restaurantes (MEDEIROS et al., 2016; BELLETTI et al., 2017). Além disso, proporciona o ordenamento da governança da cadeia produtiva ligada à IG, a conservação do meio ambiente, da cultura e da tradição de uma localidade (DALLABRIDA, 2016; MORAES et al., 2017).

No que diz respeito às comunidades rurais, a IG contribui para a redução do êxodo rural, pois possibilita um incremento da economia, proporcionando um desenvolvimento do lugar, gerando empregos e mantendo sua população no local (WILKINSON et al., 2017; CEl et al., 2018; BEZERRA et al., 2019).

É consenso que a IG é um instrumento que possibilita benefícios econômicos a uma região, porém, esses benefícios não acontecem automaticamente, dependem de fatores internos e externos como organização dos produtores, apoio 
das instituições que promovem as IGs e de políticas que possibilitem a implantação e consolidação de IG (MAIORKI e DALLABRIDA, 2015; MEDEIROS et al., 2016; GIESBRECHT e MINAS, 2019).

Apesar de existir o debate sobre a contribuição das IGs como estratégia para o desenvolvimento regional, não se pode garantir que esse desenvolvimento aconteça a partir do registro de uma IG (RINALLO e PITARDI, 2019). Existem dificuldades a serem superadas como o desconhecimento desse instrumento por parte dos consumidores, custos altos da produção devido às normas de qualidade que aumenta o valor do produto final e, em alguns casos, a baixa escala de produção devido às particularidades da produção. Para superar essas dificuldades são necessárias diversas ações, dentre elas a promulgação de políticas públicas que estimulem as IGs após o registro (KEGEL; CARLS, 2015; BELLETTI et al., 2017; PELLIN, 2019).

Os efeitos negativos de uma IG podem ocorrer uma exclusão de alguns pequenos produtores que gostariam de participar, mas não podem por não conseguirem atender as regras estabelecidas (CONEJERO e CÉSAR,2017; RINALLO e PITARDI, 2019). Regras muito flexíveis e confusas podem levar a substituição de recursos específicos por outros, visando simplificar o processo de produção, o que poderá levar a superexploração de alguns recursos com a perda de biodiversidade e também a perda da qualidade do produto. Outro efeito negativo é de que atores externos com maior poder possam retirar valor agregado da área de produção ao retirar recursos e instalações da área da IG, prejudicando o seu desenvolvimento e a sua sustentabilidade (VANDERCANDELAERE et al., 2010).

Existem riscos ligados à IG, conforme Maiorki e Dallabrida (2015) como, por exemplo, o do sistema de produção não conseguir atender ao crescimento da demanda do produto e levar a uma abusiva exploração de recursos naturais. Por tudo isso, o sucesso de uma IG depende da presença das instituições de apoio e de políticas públicas voltadas para a sua promoção e desenvolvimento (BELLETTI et al., 2017; RINALLO e PITARDI, 2019).

Para Inhan (2019), a implementação de uma IG ocorre em três fases: préimplementação, implementação e pós-implementação. Nas três fases ocorrem gargalos. Na pré-implementação, o grande gargalo é superar os desafios de cumprir as exigências sanitárias porque alguns produtores não enxergam a necessidade de atender a essas exigências, além disso é necessário criar embalagens e rótulos adequados para a comercialização do produto.

$\mathrm{Na}$ fase de implementação, o gargalo é informar aos produtores sobre o que é uma IG e conscientizá-los sobre a necessidade de se associarem, já que muitos enxergam o outro produtor como um concorrente. Para Da Silva et al., (2017) outro grande gargalo está relacionado à normatização e padronização do processo de produção, a fim de garantir a manutenção da qualidade do produto.

Durante a definição das normas de regulamentação de uma IG surgem alguns conflitos como: discordância em inserir uma prática que é utilizada por alguns produtores, exclusão de alguns produtores devido às regras fora da realidade local, definição das características de um produto que mudou ao longo do tempo. No caso de produtos artesanais, alguns motivos de conflito são: definir quando existe diversidade dos produtos e forma de fazer, qual produto e prática 
escolher e quando cada um tem uma receita como segredo de família (SCHNEIDER et al., 2017).

$\mathrm{Na}$ pós-implementação o gargalo é criado quando as instituições que fomentaram o registro de IG se afastam e os produtores não estão completamente envolvidos com a IG a ponto de usá-la como estratégia mercadológica e por não terem o retorno esperado acabam abandonando a IG (INHAN, 2019).

É evidente que uma IG pode proporcionar diversos benefícios a uma localidade, porém existem muitos desafios a serem superados no processo de estruturação que dependem da atuação coletiva de todos os agentes envolvidos de forma a analisar todos os impactos positivos e negativos e escolher as melhores estratégias para superar os desafios e garantir a sustentabilidade da IG.

\section{Procedimentos metodológicos}

A fim de caracterizar a pesquisa, pode-se dizer que ela detém caráter exploratório, com uma abordagem qualitativa e sua natureza foi aplicada. A pesquisa foi sustentada na metodologia de estudo de caso, com coleta de dados secundários a partir de relatórios e dados coletados nos endereços eletrônicos do Instituto Brasileiro de Geografia e Estatística (IBGE), do Instituto Nacional de Propriedade Industrial (INPI), do Ministério da Agricultura, Pecuária e Abastecimento (MAPA), do Serviço Brasileiro de Apoio às Micro e Pequenas Empresas (SEBRAE), da Superintendência de Estudos Econômicos e Sociais da Bahia (SEI) e demais instituições relevantes para a comprovação de notoriedade do produto.

A metodologia utilizada para embasar este estudo foi a do círculo virtuoso de qualidade ligado à origem desenvolvido pela Organização das Nações Unidas para Alimentação e Agricultura (VANDERCANDELAERE et al., 2010).

O círculo virtuoso para IG é composto de cinco fases:

1. identificação de recursos locais - realiza a avaliação dos produtos locais com potencial para registro de IG e a conscientização dos produtores;

2. qualificação do produto - determina as regras que irão garantir a qualidade do produto e preservar os recursos locais;

3. remuneração - estabelece critérios para a produção e comercialização de maneira que garanta a rentabilidade adequada e a sustentabilidade da produção;

4. reprodução local dos recursos - identifica recursos para reprodução sustentável, de forma que os recursos para a produção sejam renovados, preservados e aprimorados, além de exercer impacto positivo nas demais atividades econômicas e sociais do local;

5. políticas públicas - sistema de apoio para todas as fases através de estruturas institucionais e legais que promovam o desenvolvimento de produtos locais (VANDERCANDELAERE et al., 2010).

Tomando como base as etapas do círculo virtuoso e os estudos realizados pelo SEBRAE, os dados foram coletados em contatos com o SEBRAE e em visitas técnicas para identificar os entraves e sugerir estratégias e/ou ações para superálos, e também para indicar possíveis encaminhamentos a fim de aproveitar as oportunidades em relação ao registro de IG, na modalidade de Indicação de Procedência, para os biscoitos de Vitória da Conquista. 
Figura 2. Círculo virtuoso da qualidade vinculado à origem

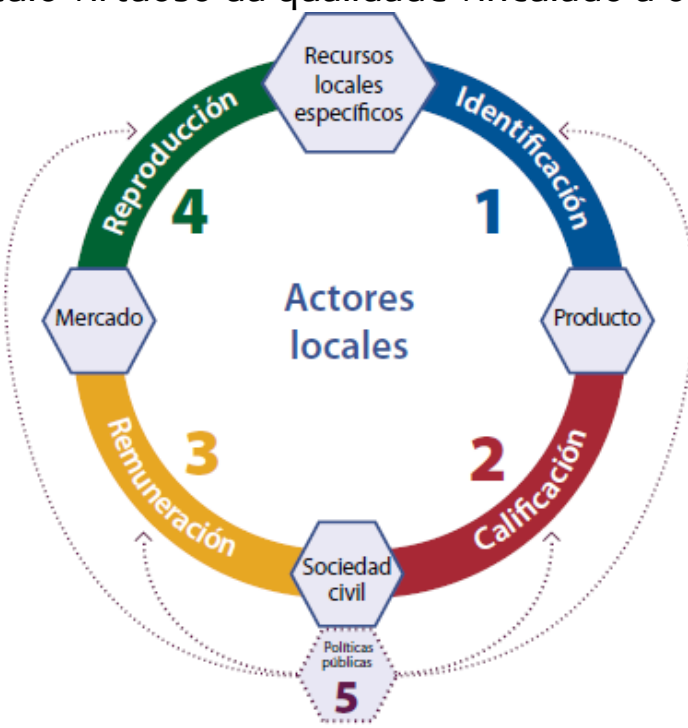

Fonte: Vandercandelaere et al. (2010, p.21)

Foram realizadas quatro visitas técnicas entre os meses de 05/2020 a 12/2019 e para foram escolhidos 11 empreendimentos produtores de biscoitos em Vitória da Conquista formalizados com CNPJ. Essa amostra representa $27 \%$ do total de produtores formais existentes na cidade, conforme SEBRAE (2019).

Foi utilizada a Análise de Conteúdo para a análise das informações coletadas. A Análise de Conteúdo, segundo Bardin (2010), se constitui em uma metodologia de pesquisa usada para descrever e interpretar o conteúdo de toda classe de documentos e textos.

\section{0 município e a produção dos biscoitos artesanais}

O município de Vitória da Conquista, localizado no estado da Bahia (Brasil) está localizado na meso região do Centro Sul Baiano, com altitude de 929,23 metros, a 509 km da capital baiana, Salvador. O clima é tropical de altitude (IBGE, 2017).

As principais atividades econômicas do município estão concentradas no ramo de serviços, representando $79 \%$ do valor agregado do Produto interno Bruto (PIB), seguidos de $18 \%$ no ramo da indústria, e $3 \%$ no ramo da agropecuária. No ramo de serviços, tem destaque o setor de educação, que consolidou Vitória da Conquista como polo de universidades e faculdades da região. O município é o terceiro mais populoso do estado, com cerca de 300 mil habitantes (SEI, 2017).

De acordo com pesquisa realizada por Novaes e Queiroz (2017), a produção de biscoitos em Vitória da Conquista é uma atividade desenvolvida há aproximadamente um século. A produção da goma e da farinha de mandioca é fruto do trabalho de muitas famílias da região por várias gerações. O amido e a fécula de mandioca são produtos essenciais para a produção dos biscoitos fabricados no município. A pesquisa também catalogou os bairros e loteamentos onde ocorrem a produção dos biscoitos na cidade, sendo eles: Ibirapuera, Alto Maron, Centro, 
Jurema, Recreio, Candeias, Boa Vista, Patagônia Campinhos, loteamento Jardim Guanabara, bairro Boa Vista.

Assim, a produção de biscoitos em Vitória da Conquista faz parte de tradição familiar, passada de geração em geração há décadas. Inicialmente essas famílias produziam a goma e a farinha de mandioca, depois passaram a fabricar os biscoitos artesanais. A fabricação é realizada com equipamentos simples e a distribuição da produção acontece por meio de veículos variados (carros pequenos, carros com carrocerias e vans) para pontos de vendas como mercearias, padarias, feiras livres, supermercados e hortifrúti. Os biscoitos têm alcançado outras regiões chegando em diferentes cidades pelo país, entre elas, Salvador, Recife, São Paulo, Teófilo Otoni e Brasília (NOVAES; QUEIROZ, 2017).

Para Sampaio et al. (2012), a cadeia produtiva da produção caseira de biscoitos na cidade funciona desde a produção de polvilho na zona rural do município até a distribuição dos biscoitos na região Sudoeste da Bahia e em outras cidades do país. Essa produção caseira se enquadra como uma possibilidade de economia solidária na mobilização de recursos internos e externos, na reestruturação de forças produtivas locais que poderá levar a região de Vitoria da Conquista a um desenvolvimento compatível com sua demografia, potencial econômico e localização geográfica.

Conforme SEBRAE (2008), a cadeia produtiva de determinado produto apresenta um longo percurso que vai desde as matérias-primas utilizadas na fabricação até o consumidor final. De acordo com o Estudo de Mercado sobre biscoitos caseiros/não industrializados desenvolvido pelo SEBRAE em 2008, na cadeia produtiva de biscoitos caseiros, foram identificadas quatro etapas sendo elas: matérias-primas, produção, comercialização/distribuição e consumidor final.

O SEBRAE tem protagonizado as ações em prol do aprimoramento da cadeia produtiva dos biscoitos em Vitória da Conquista. Em 2018, esse órgão promoveu eventos para apresentar o Projeto Biscoito Caseiro, de sua iniciativa, e do Movimento Pró-Conquista, com a participação da Prefeitura e outros atores, tais como: associações comerciais e industriais, bancos, instituições de educação, prefeitura, dentre outros (SEBRAE, 2018).

Conforme informações fornecidas pelo Gestor SEBRAE em Vitória da Conquista, em contato realizado em 10/05/19, o volume de produção dos biscoitos de Vitória da Conquista é de mais de 4000 toneladas por ano, com mais de 600 varejistas e atacadistas vivendo da produção desse produto no município. Os produtores e comerciantes se concentram no Centro de Abastecimento (Ceasa) da cidade onde existem aproximadamente 30 barracas que comercializam biscoitos de variados tipos, doces e salgados, com produção industrial e caseira. Além disso, foi informado que os biscoitos produzidos no município têm importância para a cultura local e para o PIB de Vitória da Conquista, pois, movimenta cerca de R\$ 70 milhões, considerando apenas a fase de produção. Se forem consideradas todas as etapas da cadeia produtiva esse valor é bem mais expressivo. 


\section{Entraves e oportunidades para o registro de Indicação de Procedência dos Biscoitos Artesanais de Vitória da Conquista}

Para construção do panorama relativo aos entraves e oportunidades para o registro de Indicação de Procedência dos biscoitos de Vitória da Conquista, como já foi dito, além de leituras de textos acadêmicos e documentos, foram feitos contatos com o SEBRAE e visitas técnicas aos produtores. Como síntese dos contatos feitos com o SEBRAE, pode-se dizer que o SEBRAE é notadamente o principal agente articulador de ações para promover as discussões em torno da IG dos biscoitos de Vitória da Conquista. Outros agentes somam-se nesta articulação, tais como o Movimento Pro-Conquista, a Prefeitura e a Câmara de Vereadores, com a promulgação da Lei Municipal n²320/2019 (Vitória da Conquista, 2019).

Por parte dos produtores não foi observada claramente a predisposição para organizarem-se como Associação ou Cooperativa, passo essencial para iniciar o processo de solicitação do registro de IG, embora um embrião neste sentido tenha surgido na reunião entre SEBRAE e produtores, em 06/11/19, já que a maioria dos produtores presentes concordou sobre a necessidade de se organizarem em associação. Nas visitas técnicas não foram esclarecidos dois outros aspectos fundamentais para o registro de IG: as discussões acerca da delimitação espacial relacionada à IG refletindo sobre a pertinência de incluir ou não outros municípios; e as discussões acerca da natureza e identidade do produto, qual ou quais "biscoitos" seriam protegidos.

Verifica-se que algumas ações vêm sendo tomadas através de iniciativas do SEBRAE para conscientização dos produtores e promoção da IG. Porém, existem muitos desafios que precisam ser superados o que vai requerer o empenho de todos os agentes envolvidos na cadeia produtiva desse produto, e demais agentes externos interessados nos resultados que poderão ser obtidos a partir do registro dessa IG.

A seguir são detalhados os entraves e oportunidades para o registro de Indicação de Procedência dos biscoitos de Vitória da Conquista com base nas fases do círculo virtuoso.

Fase 1 do círculo virtuoso - Identificação de recursos locais

A primeira fase do círculo virtuoso é a fase de identificação dos recursos locais; requer que sejam identificados o produto, o seu vínculo com o território e os atores envolvidos. O vínculo do produto com o território é estabelecido pela tradição na forma de fazer que faz parte da cultura da região com as receitas sendo passadas de geração em geração das famílias dos produtores de biscoitos. Dessa forma, pode-se dizer que o saber fazer é o que estabelece o vínculo dos biscoitos com a região de Vitória da Conquista.

Porém, segundo os dados coletados, essa tradição não se limita apenas ao município de Vitória da Conquista, pois se estende a municípios vizinhos. O território precisa ser delimitado e esse ponto requer análise cuidadosa já que existem produtores instalados dentro e fora do município de Vitória da Conquista. Existem produtores que fazem parte do Projeto Biscoito Caseiro do SEBRAE e que possuem pontos de vendas em Vitória da Conquista, mas produzem em municípios vizinhos. 
Portanto, no momento de delimitar a área da IG é necessário realizar um levantamento de todos os produtores que gostariam de participar de uma Associação representativa deles. Este requisito é corroborado nos trabalhos de Niederle at. al. (2016) e Pereira et al. (2018).

Outro aspecto a considerar é que o saber fazer os biscoitos - que lhe dá características específicas - pode não estar apenas vinculado ao município de Vitória da Conquista. A delimitação da área requer estudo para identificar quais municípios produzem da mesma forma e que gostariam de participar de uma entidade representativa. Estas questões foram apoiados nos trabalhos de Dallabrida (2016) e Moraes et al. (2017).

Quanto à identificação do biscoito característico da região, devido à variedade de biscoitos produzidos não foi possível determinar um especificamente. Será necessário realizar debates e estudos com os produtores e demais atores envolvidos na cadeia produtiva para determinar um tipo ou mais de um tipo de biscoito que represente o saber fazer da região. A diversidade dos biscoitos indica que futuramente poderá haver dificuldades para os produtores entrarem em consenso sobre quais biscoitos deverão ser protegidos, o que poderá requerer intermediação de atores externos envolvidos na promoção dessa IG.

Os atores diretamente envolvidos no processo de produção foram identificados como pequenos e médios produtores, fornecedores de matériasprimas que estão localizados dentro e fora do município de Vitória da Conquista.

Fase 2 do círculo virtuoso - Qualificação do Produto

A segunda fase do círculo virtuoso é a de qualificação do produto com informações sobre o processo de produção e a gestão da qualidade do produto. Verificou-se que são utilizados sistemas de produção artesanal e semi-industrial, variando de acordo com o tamanho do negócio e tipos de biscoitos produzidos. Não existe padronização do controle de qualidade de acordo com as especificações do produto. Cada produtor faz o que lhe é pertinente ou o que está relacionado às exigências da vigilância sanitária.

Após definir os tipos de biscoitos que serão protegidos pela IG, será necessário estabelecer as regras de produção e controle de qualidade, levando em consideração que regras muito rígidas podem levar à exclusão de produtores que não poderão cumpri-las devido aos custos de produção que podem ser elevados. Por outro lado, regras muito flexíveis podem levar à queda da qualidade do produto. Por isso, é necessário haver um equilíbrio, estabelecer regras e especificações que possam ser cumpridas e que garantam a qualidade do produto. Essas regras devem ser construídas com a participação de representantes de todas as fases da cadeia produtiva. Estas condições são legitimadas por Giesbrecht \& Minas (2019) e Caldas et al. (2017).

As regras e as especificações devem permitir: identificar e definir as práticas de produção de maneira precisa, garantir a qualidade do produto e a confiança do consumidor, evitar que pessoas prejudiquem a reputação da IG comercializando produtos de qualidade inferior usando a fama e reputação da IG. Regras bem estabelecidas evitam que produtores instalados fora da área da IG possam usar indevidamente o nome da IG (Vandercandelaere et al., 2010). 
As regras precisam descrever o produto através de características físicas, químicas ou organolépticas, relacionar as matérias-primas utilizadas, definir todas as fases do processo de produção, determinar as proibições, descrever a área de produção de matérias-primas, processamento e condicionamento, além de descrever como os controles serão realizados (Vandercandelaere et al., 2010).

No momento de estabelecer as regras será necessária a intermediação de agentes externos. A atuação do SEBRAE, Prefeitura e Movimento Pró Conquista será de grande importância nessa fase porque conflitos poderão surgir já que os produtores possuem seus métodos específicos de produção e podem se sentir prejudicados no momento de compartilhar e definir qual método será o mais adequado para constar no Caderno de Especificações da IG. Os critérios e regras bem elaboradas são confirmados nos trabalhos de Conejero \& César (2017) e Rinallo \& Pitardi (2019).

Será necessário criar um Conselho Regulador para realizar o controle através do acompanhamento e monitoramento da IG, para garantir que as regras sejam cumpridas e também para buscar estratégias que garantam a sustentabilidade da IG. Esse Conselho deve ser composto por vários atores que fazem parte da cadeia produtiva e instituições ligadas à promoção da IG.

Para administrar ou evitar alguns conflitos, é importante que a composição do Conselho Regulador tenha uma composição equilibrada com representantes de toda a cadeia produtiva e agentes externos envolvidos na promoção da IG. A gestão deve ser feita de forma democrática e transparente, estabelecendo contribuição econômica de forma justa de cada um dos membros, calculando com base nos custos e benefícios com pagamento proporcional ao volume dos serviços. Isso requer comprometimento e cooperação de todos os entes que deverão assumir responsabilidades em prol do desenvolvimento da IG (Vandercandelaere et al., 2010).

Fase 3 do círculo virtuoso - Remuneração

A terceira fase do círculo virtuoso trata da remuneração e comercialização do produto. Essa fase garante a sustentabilidade da IG. Faz-se necessário conhecer o mercado, as demandas dos consumidores, traçar as estratégias de marketing para promoção e comercialização do produto (Vandercandelaere et al., 2010).

Os produtores adotam diferentes margens de lucro, e informaram que a maior dificuldade encontrada na comercialização é competir com o preço da concorrência, que, na maioria das vezes, produz de forma clandestina, sem os custos de produção de que quem produz formalmente.

A maioria dos produtores contatados comercializam seus produtos apenas dentro do município de Vitória da Conquista. Poucos conseguem alcançar outras cidades e estados. Quanto às estratégias de divulgação ficou evidente que a maioria dos produtores contatados não possui definição de estratégia para divulgar e promover o produto. Portanto, será necessário promover estratégia de marketing para divulgação do produto e alcance de novos mercados. Além disso, será necessário desenvolver embalagens e rotulagens adequados, pois não existe padronização nas embalagens utilizadas e os rótulos não oferecem as informações 
nutricionais necessárias. Estas e outras estratégias são informados pelos autores Medeiros et al., (2016) e Niederle at. al., (2017) em suas obras.

Embalagens e rótulos adequados agregam valor ao produto pois garantem uma melhor conservação e transporte para longas distâncias, permite que os consumidores tenham as informações nutricionais necessárias sobre o produto que estabelecem a relação de garantia da qualidade e origem dele. Já a marca, permite que aos consumidores identificar a empresa que produz o produto e também cria a reputação dele. Alguns produtores não têm condições de assumir o custo de promoção de uma marca individual, por isso um selo vinculado à IG se torna uma opção mais viável. Os custos de produção e comercialização do produto definem o preço mínimo que deve ser aplicado. O cálculo do preço correto deve levar em conta as expectativas de lucro dos produtores, o preço da concorrência e a preferência dos consumidores que está atrelada a qualidade/preço (Vandercandelaere et al., 2010).

Questões como cálculo de preço que garanta lucratividade, estratégias para divulgação e promoção do produto, embalagens e rótulos adequados, logística de distribuição e comercialização em novos mercados são entraves que precisam ser superados pelos produtores de biscoitos. Por isso, a criação de uma Associação ou Cooperativa para debater e buscar coletivamente soluções para essas questões é de suma importância. Essas questões precisam ser amadurecidas e resolvidas e só depois se pensar em registro de IG. A sustentabilidade da IG requer a consolidação de uma entidade representativa, assim como resolução dos gargalos.

Fase 4 do círculo virtuoso - Reprodução local dos recursos

A quarta fase do círculo virtuoso trata da reprodução local dos recursos com análise sobre a origem da matéria-prima e sobre a inter-relação dos produtores. A reprodução sustentável dos recursos consiste em garantir que tanto os recursos humanos quanto os naturais sejam preservados e melhorados, e garantir a sustentabilidade econômica, social e ambiental da IG. Isso requer a redistribuição de valor e remuneração em toda a cadeia produtiva de forma a remunerar todos os atores de acordo com a sua contribuição e criação de valor ao produto (Vandercandelaere et al., 2010).

Os produtores contatados utilizam matérias-primas naturais e industrializadas com origem dentro e fora do município. Devido à variedade dos biscoitos, os ingredientes são diversificados, variando de acordo com o tipo do biscoito e a escala de produção. São utilizadas matérias-primas como: polvilho, açúcar, queijo, ovos, leite, frutas, gordura vegetal, manteiga, além de produtos químicos que dão crocância e conservação aos biscoitos.

A maioria dos produtores contatados adquirem suas matérias-primas dentro e fora do município, apenas $36 \%$ adquire seus ingredientes apenas no município. Isso evidencia a necessidade de estímulos para que sejam produzidos no município a maior parte das matérias-primas utilizadas na produção dos biscoitos, tais como: polvilho, ovos, leite e queijo.

As matérias-primas são obtidas através de pequenos produtores, fecularias oriundos do estado do Paraná, rede de supermercados, atacadistas, distribuidores e fábrica de embalagens. Chamou à atenção o fornecimento de polvilho por fecularias 
de outro estado do país, o que demonstra que não existe produção de polvilho na região para atender a demanda de produção dos biscoitos.

É preciso aproveitar o potencial dos biscoitos para gerar emprego e renda para os pequenos e médios produtores da região. São necessárias ações e políticas para promover o fortalecimento da cadeia produtiva, principalmente políticas de incentivo aos pequenos produtores de matérias-primas. Incentivo à produção do polvilho para atender à demanda de produção dos biscoitos e, com isso, gerar emprego e renda nos municípios produtores.

Há diversos relatos de casos que demonstram a relação entre turismo rural e produtos protegidos por IG, por isso espera-se que o desenvolvimento de uma IG contribua para o desenvolvimento do turismo na região delimitada pela IG. A interação ocorre através de eventos culturais que representem a região e combinem à tradição do produto à cultura e, com isso, estimule o desenvolvimento da economia e da sociedade local. A interação de políticas públicas entre setores da agricultura e turismo é importante em nível local e nacional, porque dá visibilidade tanto ao produto quanto ao local (Vandercandelaere et al., 2010).

Nesse aspecto a região de Vitória da Conquista possui potencial para desenvolver alguns circuitos turísticos, pois já existem eventos que acontecem na cidade com atração de grandes públicos locais e regionais, tais como o Festival de Inverno e Feiras de Exposições. A Semana do Biscoito que foi instituída recentemente fará parte do calendário de comemorações da cidade e servirá para divulgar o produto de uma possível futura IG.

Quanto aos recursos humanos, foi informado por alguns produtores que o mercado não possui mão de obra especializada para atividade de produção de biscoitos, por isso mesmo, essa mão de obra não é valorizada. Os produtores treinam os funcionários para desenvolverem as atividades, alguns desses funcionários ao dominar todas as fases de produção montam a sua própria "fabriqueta" passando a produzir, na maioria das vezes, de forma clandestina.

As estratégias para o desenvolvimento e fortalecimento da cadeia produtiva dos biscoitos requer a participação de vários atores ligados a instituições públicas e privadas de diferentes setores da economia. Será necessário estabelecer parcerias entre o poder público, instituições de ensino e o SEBRAE para solucionar alguns entraves da cadeia produtiva dos biscoitos.

Fase 5 do círculo virtuoso - Políticas Públicas

A quinta e última fase do círculo virtuoso trata do conhecimento sobre IG e a relação das políticas públicas na promoção da IG. O interesse público deve garantir que essas políticas levem em consideração não apenas os aspectos econômicos, mas, também os aspectos sociais, culturais e ambientais. O poder público deve atuar em todas as fases de implantação da IG através da sensibilização sobre a importância da IG, colaborar na realização de estudos de viabilidade, no plano de comunicação, além de incentivos para à produção, assegurando a representação equilibrada dos atores da IG, atuar como intermediador nos possíveis conflitos e incentivar os produtores a levar em conta os recursos locais (Vandercandelaere et al., 2010). 
Conforme informado pelos produtores contatados, não existe nenhum instrumento do poder público de apoio aos produtores de biscoitos. Em termos de políticas públicas voltadas para o incentivo e fortalecimento da cadeia produtiva do biscoito só foi identificada a Lei Municipal $n^{\circ}$ 2320/2019 que instituiu a Semana do Biscoito no calendário de comemoração da cidade. Todas as ações de incentivo e fortalecimento da cadeia produtiva do biscoito vêm sendo promovidas pelo SEBRAE. A Prefeitura tem apoiado o SEBRAE nas ações do Projeto Biscoito Caseiro.

Será necessário discutir e esclarecer aos produtores e sociedade em geral sobre o que é uma IG, suas vantagens e desvantagens, uma vez que os produtores contatados demonstraram não ter o conhecimento do que seja uma IG, como funciona e o que requer dos produtores. Apenas os produtores contatados que fazem parte do Projeto Biscoito Caseiro já tinham ouvido falar sobre IG através do SEBRAE.

De acordo com Vandecandelaere et al. (2010), as principais vantagens em fazer parte de uma IG são: impedir a concorrência desleal através das regras estabelecidas, maior visibilidade do produto com possibilidade de alcançar novos mercados e aumentar as vendas, compartilhamento de serviços e diminuição de custos. Mas também há desvantagens, e as principais desvantagens são: interdependência com outros produtores e estratégias coletivas que podem gerar conflitos, taxa de associação e custos para se adaptar às especificações.

É necessário que o poder público municipal se aproprie das demandas para o estímulo e conscientização dos produtores sobre os benefícios e consequências da IG e com isso promover o registro. Como o SEBRAE possui orçamento limitado para - Projeto Biscoito Caseiro, o poder público municipal precisa assumir a responsabilidade de desenvolver ações para estimular e fortalecer toda a cadeia produtiva dos biscoitos uma vez que é interesse do município promover emprego, renda e consequentemente desenvolvimento local. A questão das ações efetivas das políticas públicas para o fomento da cadeia de um IG é corroborado pelas obras de Kegel \& Carls (2015), Belletti et al. (2017), Pellin (2019), Belletti et al., (2017) e Rinallo \& Pitardi (2019).

A atuação de atores públicos é necessária para garantir a regulamentação de instrumentos e apoiar a gestão da IG através de políticas de incentivo e criação de condições favoráveis para a produção do produto. O poder público também deve desenvolver estudos econômicos, sociais e ambientais para verificar os impactos positivos e negativos da IG e traçar as estratégias para estimular os impactos positivos e minimizar os negativos. A combinação de iniciativas públicas e privadas garantirá que o sistema de IG funcione corretamente (Vandercandelaere et al., 2010).

\section{Estratégias para superação dos gargalos e aproveitamento das oportunidades}

Pode-se considerar que os biscoitos de Vitória da Conquista demonstram potencial econômico, pois é um segmento de mercado que movimenta cerca de R\$ 70 milhões por ano. Além disso, o produto possui características como sabor e textura que faz com que os consumidores o percebam e o reconheçam, dando-lhe notoriedade. 
A ação coletiva é fundamental no processo de estruturação de uma IG desde a fase de identificação, por isso, é necessário que os produtores estejam agrupados através de entidades como Associação ou Cooperativa. Como já informado não existe associação de produtores constituída nem qualquer outra forma de entidade representativa dos produtores de biscoitos em Vitória da Conquista e esse é o principal gargalo para a IG dos Biscoitos de Vitória da Conquista, uma vez que é a entidade representativa que solicita o registro. Além disso, uma IG requer atuação coletiva em todas as fases de sua promoção.

A criação de uma Associação ou Cooperativa de produtores dos biscoitos de Vitória da Conquista é fundamental e urgente. É o passo inicial em direção à estruturação da IG dos Biscoitos.

O quadro 1 representa a síntese dos entraves e oportunidades identificados, bem como as estratégias propostas.

Quadro 1. Síntese dos entraves e oportunidades identificados e as estratégias propostas

\begin{tabular}{|c|c|c|}
\hline $\begin{array}{l}\text { DIMENSÃO DO } \\
\text { CÍRCULO VIRTUOSO }\end{array}$ & ENTRAVES OU OPORTUNIDADES & ESTRATÉGIAS PROPOSTAS \\
\hline \multirow{4}{*}{$\begin{array}{l}\text { IDENTIFICAÇÃO DE } \\
\text { RECURSOS LOCAIS }\end{array}$} & $\begin{array}{l}\text { O produto possui potencial de mercado } \\
\text { e notoriedade. }\end{array}$ & - \\
\hline & $\begin{array}{l}\text { O saber fazer é o que estabelece o } \\
\text { vínculo dos biscoitos com o território. }\end{array}$ & ----- \\
\hline & $\begin{array}{l}\text { Pequenos e médios produtores estão } \\
\text { localizados dentro e fora do município } \\
\text { de Vitória da Conquista. }\end{array}$ & $\begin{array}{l}\text { Delimitação da área de produção através de levantamento que } \\
\text { englobe os atuais produtores e os potenciais que futuramente } \\
\text { poderão fazer parte da IG. }\end{array}$ \\
\hline & $\begin{array}{l}\text { Grande variedade de biscoitos } \\
\text { produzidos. }\end{array}$ & $\begin{array}{l}\text { Realizar debates com os produtores e demais atores } \\
\text { envolvidos na cadeia produtiva para determinar um tipo ou } \\
\text { mais de um tipo de biscoito que represente o saber fazer da } \\
\text { região e que serão protegidos pela IG. }\end{array}$ \\
\hline \multirow{4}{*}{$\begin{array}{l}\text { QUALIFICAÇÃO DO } \\
\text { PRODUTO }\end{array}$} & \multirow{4}{*}{$\begin{array}{l}\text { Não existe padronização do controle de } \\
\text { qualidade de acordo com as } \\
\text { especificações do produto. Cada } \\
\text { produtor faz o que lhe é pertinente. }\end{array}$} & $\begin{array}{l}\text { Elaborar as regras para a produção dos biscoitos escolhidos } \\
\text { com definição das matérias-primas que serão utilizadas, sua } \\
\text { origem, receitas/forma de fazer e controle de qualidade. }\end{array}$ \\
\hline & & $\begin{array}{l}\text { Estabelecer as regras de produção e controle de qualidade que } \\
\text { possam ser cumpridas e que garantam a qualidade do produto. } \\
\text { Essas regras devem ser construídas com a participação de } \\
\text { representantes de todas as fases da cadeia produtiva. Será } \\
\text { necessário a intermediação de agentes externos como o } \\
\text { SEBRAE. }\end{array}$ \\
\hline & & $\begin{array}{l}\text { Montar o Caderno de Especificação com base no Regulamento } \\
\text { da IG de São Tiago que é a única IG de biscoitos atualmente no } \\
\text { Brasil. }\end{array}$ \\
\hline & & $\begin{array}{l}\text { Constituir Conselho Regulador com composição equilibrada, } \\
\text { com representantes de toda a cadeia produtiva e agentes } \\
\text { externos envolvidos na promoção da IG. }\end{array}$ \\
\hline \multirow{3}{*}{ REMUNERAÇÃO } & $\begin{array}{l}\text { São praticadas diferentes margens de } \\
\text { lucro. A maior dificuldade encontrada na } \\
\text { comercialização é competir com o preço } \\
\text { da concorrência. }\end{array}$ & $\begin{array}{l}\text { Cálculo do preço mínimo de acordo com os custos de } \\
\text { produção e comercialização do produto. }\end{array}$ \\
\hline & $\begin{array}{l}\text { A maioria dos produtores contatados } \\
\text { comercializam seus produtos apenas } \\
\text { dentro do município }\end{array}$ & $\begin{array}{l}\text { Desenvolver plano de marketing para divulgação e } \\
\text { comercialização dos biscoitos em novas praças. }\end{array}$ \\
\hline & $\begin{array}{l}\text { Não existe padronização nas } \\
\text { embalagens utilizadas e os rótulos não } \\
\text { oferecem as informações nutricionais } \\
\text { necessárias. }\end{array}$ & $\begin{array}{l}\text { Desenvolver parcerias com Universidades para análise } \\
\text { nutricional dos biscoitos e composição dos rótulos; utilizar } \\
\text { embalagens adequadas; criar marca para os biscoitos. }\end{array}$ \\
\hline \multirow[b]{2}{*}{$\begin{array}{l}\text { REPRODUÇÃO } \\
\text { LOCAL DOS } \\
\text { RECURSOS }\end{array}$} & Produtores não estão associados & Constituir uma entidade representativa. \\
\hline & $\begin{array}{l}\text { Utilizam matérias-primas naturais e } \\
\text { industrializados com origem dentro e } \\
\text { fora do município. Apenas } 36 \% \text { adquire } \\
\text { seus ingredientes apenas no município. }\end{array}$ & $\begin{array}{l}\text { Estimular ações, através de do poder local, para promover o } \\
\text { fortalecimento da cadeia produtiva. Criar políticas de incentivo } \\
\text { aos pequenos produtores das principais matérias-primas } \\
\text { como: polvilho, ovos, leite e queijo, para atender à demanda } \\
\text { de produção dos biscoitos e com isso, gerar emprego e renda } \\
\text { nos municípios produtores. }\end{array}$ \\
\hline
\end{tabular}




\begin{tabular}{|c|c|c|}
\hline & $\begin{array}{l}\text { Falta mão de obra especializada para } \\
\text { atividade de produção de biscoitos. }\end{array}$ & \begin{tabular}{|l} 
Promover parceria, através do Poder público, com as \\
instituiç̧̃̃es de ensino, para oferecer cursos de capacitação \\
para formação de mão de obra qualificada.
\end{tabular} \\
\hline \multirow{6}{*}{ POLÍTICAS PÚBLICAS } & Desconhecimento sobre o tema IG & $\begin{array}{l}\text { Criar agenda de discussões e palestras para esclarecer aos } \\
\text { produtores e sociedade em geral sobre o que é uma IG, como } \\
\text { funciona, suas vantagens e desvantagens para quem faz parte. }\end{array}$ \\
\hline & \multirow{5}{*}{$\begin{array}{l}\text { Faltam políticas públicas de apoio aos } \\
\text { produtores de biscoitos e demais } \\
\text { agentes da cadeia produtiva. }\end{array}$} & $\begin{array}{l}\text { Desenvolver políticas e parcerias, através do Poder Municipal, } \\
\text { com algumas instituições para estimular os pequenos } \\
\text { produtores de matérias-primas e fortalecer toda a cadeia } \\
\text { produtiva dos biscoitos e, com isso, possibilitar a geração de } \\
\text { emprego e renda no município e região. }\end{array}$ \\
\hline & & $\begin{array}{l}\text { Estabelecer parcerias com Instituições de Ensino locais para } \\
\text { desenvolver estudos para promover melhorias tecnológicas no } \\
\text { sistema de produção e aumento da produtividade garantindo a } \\
\text { qualidade e às características tradicionais do saber fazer os } \\
\text { biscoitos. }\end{array}$ \\
\hline & & $\begin{array}{l}\text { Estabelecer parcerias com outros municípios e dessa forma } \\
\text { beneficiar toda a região que está inserida na produção dos } \\
\text { biscoitos. }\end{array}$ \\
\hline & & $\begin{array}{l}\text { Solicitar ao Governo do Estado um estudo sobre a viabilidade } \\
\text { de um APL do Café com Biscoito, uma vez que esses dois } \\
\text { produtos são destaques na economia da regiáo. O APL traria } \\
\text { incentivos para esses dois segmentos e possibilitaria } \\
\text { desenvolvimento para toda a regiáo. }\end{array}$ \\
\hline & & $\begin{array}{l}\text { Planejar um roteiro turístico como uma" Rota do Café com } \\
\text { Biscoito" com visitas a produtores e fazendeiros, assim como } \\
\text { criação de espécie de museu ou centro cultural com } \\
\text { informações sobre produção e tradição desses dois produtos. }\end{array}$ \\
\hline
\end{tabular}

Fonte: Elaboradora pela autora com base nos resultados das visitas técnicas

A presença do SEBRAE, do Movimento Pró-Conquista, da Prefeitura e das Instituições de Ensino será fundamental para fornecer suporte aos produtores e intermediação das discussões entre eles, sozinhos, podem não dar conta, discussões relativas a temas tais como: definir os tipos de biscoitos que serão protegidos, determinar as regras de produção e elaborar o caderno de especificações, definir a área de produção, enfim, providenciar os estudos e organizar toda a documentação necessária ao registro da IG.

Essas proposições para superação dos desafios e aproveitamento das oportunidades, antes de serem apresentadas aqui, foram submetidas aos representantes dos agentes relacionados à promoção da IG dos Biscoitos de Vitória da Conquista para que fossem avaliadas.

\section{Considerações finais}

Os biscoitos de Vitória da Conquista possuem potencial para o registro de Indicação de Procedência. A cadeia produtiva dos biscoitos é um segmento de mercado consolidado no município. O produto é fruto de tradição local, cujo saber fazer vem sendo passado de geração em geração há aproximadamente um século. A notoriedade dos biscoitos é a principal característica que indica o potencial dessa IG.

Um dos principais entraves identificados na pesquisa é a falta de uma entidade que agrupe os produtores e comerciantes de biscoitos. Esse parece ser 0 principal desafio a ser superado, pois alguns outros obstáculos dependem de esse haver sido superado. Os produtores e comerciantes precisam se agrupar através de uma entidade representativa para juntos, compartilhando os custos e planejando 
estratégias, superarem os entraves apontados nessa pesquisa e iniciarem as ações necessárias à promoção da IG.

Outros entraves estão relacionados à necessidade de definição do tipo ou dos tipos de biscoitos a serem protegidos pela IG, já que há uma grande diversificação de biscoitos apontados pelos produtores contatados visando essa proteção. Também se constitui uma séria dificuldade o fato de alguns produtores contatados informarem que a sua produção dos biscoitos não é feita no município de Vitória da Conquista. Assim sendo a delimitação territorial exigida no processo de proteção de uma IG requer discussões e estudos.

É notória a falta de informação e conhecimento sobre IG entre os produtores contatados, por isso, será necessário promover discussões para esclarecimento dos agentes da cadeia produtiva e conscientização sobre a importância desse instrumento, bem como para promover as discussões acerca da necessidade de formação de uma entidade representativa para organização dos produtores e resolução de forma coletiva dos entraves que a cadeia dos biscoitos apresenta.

O registro de uma IG não traz benefícios imediatos, requer ações dos diversos atores envolvidos para a promoção contínua do sistema. Políticas públicas voltadas para o desenvolvimento local que relacione a IG com outros setores da economia local serão necessárias para criar uma rede de relacionamento e sustentação da IG.

Espera-se que as estratégias sugeridas e que foram apresentadas aos representantes dos agentes relacionados à promoção da IG dos Biscoitos de Vitória da Conquista possam contribuir para a promoção dessa IG, e que o poder público local possa tomar para si a responsabilidade de desenvolver essas e outras estratégias para promover a IG e também o desenvolvimento do município através dos benefícios que poderão surgir a partir do registro.

\section{REFERÊNCIAS}

AGOSTINO; Mariarosaria; TRIVIERI, Francesco. Geographical indication and wine exports. An empirical investigation considering the major European producers.

Food Policy, v. 46, p, 22-36, 2014. DOI:

http://dx.doi.org/10.1016/j.foodpol.2014.02.002

BARDIN, Laurence. Análise de Conteúdo. Edições 70. 2010.

BARJOLLE, Dominique; QUIN ONES-RUIZ; Xiomara F; BAGAL, Monique; COMOE, Hermann. The Role of the State for Geographical Indications of Coffee: Case Studies from Colombia and Kenya. World Development, v. 98, pp. 105-119, 2017. DOI: https://doi.org/10.1016/j.worlddev.2016.12.006

BELLETTI, Giovanni; MARESCOTTI, Andrea; TOUZARD, JEAN-MARC. Geographical Indications, Public Goods, and SustainableDevelopment: The Roles of Actors' Strategies and Public Policies. World Development, v. 98, pp. 45-57, 2017 DOI: https://doi.org/10.1016/j.worlddev.2015.05.004 
Oportunidades e Entraves Para a Proteção por Indicação de Procedência para os Biscoitos Artesanais de Vitória da Conquista-BA

BEZERRA, Maria das Graças Ferraz; SARTORI, Rejane; SANTOS, Wagna Piler Carvalho dos; AMARANTE SEGUNDO, Gesil Sampaio. Indicação Geográfica: conceitos, legislação e proposição. In Conceitos e Aplicações de Propriedade. Volume II. Organizadora Wagna Piler Carvalho dos Santos. - Salvador (BA): IFBA, 2019.

BRASIL. Instrução Normativa 095 de 28 de Dezembro de 2018. Estabelece as condições para o registro das Indicações Geográficas. Ministério da Indústria, Comércio Exterior e Serviços. Disponível em:

https://www.gov.br/inpi/pt-br/backup/centrais-deconteudo/legislacao/IN0952018.pdf. Acesso em: 20 Fev. 2019

. Lei $\mathrm{n}^{\circ}$ 9.279, de 14 de maio de 1996. Regula direitos e obrigações relativos à propriedade industrial. Diário Oficial da República Federativa do Brasil. Brasília, DF, 15 maio 1996. Seção 1, p. 8353. Disponível em:

http://www.planalto.gov.br/ccivil_03/Leis/L9279.htm. Acesso em: 25 Set. 2018.

CALDAS, Alcides dos Santos; ARAÚJO, Cristiano Cassiano de. COURY, Rafael de Lira Mansur. As Indicações Geográficas (IGs) como estratégia de desenvolvimento territorial: desafios e potencialidades no distrito de Maragogipinho, Aratuipe,BA Revista de Desenvolvimento Econômico - RDE, v. 3, n. 38, pp. 81-108, 2017. DOI: http://dx.doi.org/10.21452/rde.v3i38.5032

CEI, Leonardo; STEFANIA. Gianluca; DEFRANCESCOB. Edi; LOMBARDIA, Ginevra Virginia. Geographical indications: A first assessment of the impact on rural development in Italian NUTS3 regions. Land Use Policy, v. 75, pp. 620-630, 2018. DOI: https://doi.org/10.1016/j.landusepol.2018.01.023

CONEJERO, Marco Antonio; CÉSAR, Aldara da Silva. A Governança de Arranjos Produtivos Locais (APLS) para p Gestão Estratégica de Indicações Geográficas (IGS). Ambiente \& Sociedade. v.20 n.1, São Paulo, Jan./Mar, 2017. DOI: https://doi.org/10.1590/1809-4422asoc20160010v2012017

DALLABRIDA, Valdir Roque. Ativos territoriais, estratégias de desenvolvimento e governança territorial: uma análise comparada de experiências brasileiras e portuguesas. EURE (Santiago), v.42 n.126 Santiago, pp. 187-212, 2016. DOI: http://dx.doi.org/10.4067/S0250-71612016000200009

DA SILVA, Icaro Ribeiro Cazumba; CARDOSO, Ryzia de Cassia Vieira; GOES, Josê Angelo Wenceslau; DRUZIAN, Janice Izabel; JÚNIOR, Permínio Oliveira Vidal; ANDRADE, Alaane Caroline Benevides de. Food safety in cassava "flour houses" of Copioba Valley, Bahia, Brazil: Diagnosis and contribution to geographical indication. Food Control, $v$ 72, Part A, pp. 97-104, 2017.

DOI: https://doi.org/10.1016/j.foodcont.2016.07.034 
percebidas e aprendizados. In: VIEIRA, Adriana Carvalho Pinto; LOURENZANI, Ana Elisa Bressan Smith; BRUCH, Kelly Lissandra; LOCATELLI, Liliana; GASPAR, Ludimila Cesar Moura (Orgs.). Indicações Geográficas, Signos Coletivos e Desenvolvimento Local/Regional - Vol. 2 - Erechim: Deviant, 2019. 485 p.

GOFFIC, Caroline Le; ZAPPALAGLIO, Andrea. The Role Played by the US Government in Protecting Geographical Indications. World Development, v. 98, pp. 35-44, 2017. DOI: https://doi.org/10.1016/j.worlddev.2016.08.017

IBGE - INSTITUTO BRASILEIRO DE GEOGRAFIA E ESTATÍSTICA. Cidades. 2017. Disponível em: https://cidades.ibge.gov.br/brasil/ba/vitoria-da-conquista/panorama. Acesso em: 5 Jun. 2019

INHAN MATOS, L. A. Três gargalos que têm ocorrido na implementação das Indicações Geográficas. 2019. Disponível em: https://www.youtube.com/watch?v=yikSAGdRUq8\&list=UURiY5Q4IDxWvt8fwfdEifA\&index=5 . Acesso em: 14 Dez. 2019.

INPI - INSTITUTO NACIONAL DE PROPRIEDADE INDUSTRIAL. Guia básico de indicação geográfica. 2019a. Disponível em: https://www.gov.br/inpi/pt-br/servicos/indicacoes-geograficas/guia-basico . Acesso em: 21 Jun. 2019

2019b. - Novas normas para Indicações Geográficas entram em vigor. https://www.gov.br/inpi/pt-br/assuntos/noticias/novas-normas-para-indicacoesgeograficas-entram-em-vigor Acesso em: 21 Jun. 2019

. Pedidos de indicação geográfica concedidos e em andamento. Revista da Propriedade Industrial (RPI) n RPI 2567, de 17/03/2020. 2020. Disponível em: http://www.inpi.gov.br/menu-servicos/indicacao-geografica/pedidos-de-indicacaogeografica-no-brasil. Acesso em: 30 Mar. 2010.

KEGEL, Patrícia Luiza; CARLS, Suelen. O Instituto Jurídico da Indicação Geográfica na promoção do desenvolvimento regional: o caso dos cristais artesanais da região de Blumenau. Redes (St. Cruz Sul, Online) v. 20, n 3, p. 293-313, 2015.

DOI: https://doi.org/10.17058/redes.v20i3.4381

MAIORKI, Giovane Jose; DALLABRIDA, Valdir Roque. A indicação geográfica de produtos: um estudo sobre sua contribuição econômica no desenvolvimento territorial. Interações (Campo Grande), v.16, n.1, pp.13-25, 2015, DOI: https://doi.org/10.1590/151870122015101.

MARQUES, Bartolomeu das Neves; BULCÃO, Camila Santos; LIMA, Ângela Maria Ferreira; LOPES, Jerisnaldo Matos; SILVA, Marcelo Santana. Artefatos de Couro de Ipirá: Potencial de Indicação Geográfica no Território da Bacia Do Jacuípe - Bahia. Cadernos de Prospecção, Salvador, v. 12, n. 5, p. 1598-1611, 2019. 
Oportunidades e Entraves Para a Proteção por Indicação de Procedência para os Biscoitos Artesanais de Vitória da Conquista-BA

DOI: http://dx.doi .org/10.9771/cp.v12i5 \%20Especial.31018

MEDEIROSA, Mirna de Lima; PASSADORA Cláudia Souza; PASSADOR João Luiz. Implications of geographical indications: a comprehensive review of paperslisted in CAPES' journal database. RAI Revista de Administração e Inovação, v.13, pp 315329, 2016. DOI: http://dx.doi.org/10.1016/j.rai.2016.09.002

MORAES, Fernanda; FERREIRA, Diego; SABA, Hugo. Indicação de Procedência: potencial do Recôncavo da Bahia no reconhecimento da produção artesanal de licores de frutas. Conj. \& Planej., Salvador, n.193, p.63-77, 2017. Disponível em: http://publicacoes.sei.ba.gov.br/index.php/conjunturaeplanejamento/article/downlo ad/94/113/. Acesso em: 24 Set. 2018.

NIEDERLE, Paulo Andre; BRUCH, Kelly Lissandra; PINTO VIEIRA, Adriana Carvalho. Reconfigurações institucionais nos mercados agroalimentares: a construção dos Regulamentos de Uso das Indicações Geográficas para vinhos no Brasil. Mundo Agrário. v.17, n.36, pp 01-22, 2016. Disponível em: http://www.scielo.org.ar/pdf/magr/v17n36/v17n36a09.pdf

NIEDERLE, Paulo Andre; MASCARENHAS, Gilberto Carlos Cerqueira; WILKINSON, John. Governança e Institucionalização das Indicações Geográficas no Brasil. Revista Econômica e Sociologia Rural, v.55, n.1, Brasília, 2017.

DOI: https://doi.org/10.1590/1234-56781806-94790550105

NOVAES, Miriam de Jesus; QUEIROZ, Greiziene Araújo. O circuito inferior da economia urbana: a produção de biscoitos em Vitória da Conquista-Bahia. XII Colóquio Nacional e V Colóquio Internacional do Museu Pedagógico. Vitória da Conquista. Setembro,2017. Disponível em:

http://anais.uesb.br/index.php/cmp/article/viewFile/7058/6862. Acesso em: 06 Ago. 2019

PELLIN, Valdinho Pellin. Indicações Geográficas e desenvolvimento regional no Brasil: a atuação dos principais atores e suas metodologias de trabalho. Interações (Campo Grande), v. 20, n. 1, p. 63-78, 2019.

DOI: https://doi.org/10.20435/inter.v20i1.1792

PEREIRA, Mara Elena Bereta de Godoi, LOURENZANI, Ana Elisa Bressan Smith, Kassia Watanabe. Indicações Geográficas como estratégia de desenvolvimento: o caso do Norte Pioneiro do Paraná. Interações (Campo Grande), v.19 n.3, pp 515-528, Campo Grande, 2018. DOI: https://doi.org/10.20435/inter.v19i3.1654

RINALLO, Diego; PITARDI, Valentina. Open conflict as differentiation strategy in geographical indications: the Bitto Rebels case British. Food Journal, v. 121, n. 12, pp. 3102-3118, 2019. DOI: https://doi.org/10.1108/BFJ-11-2018-0738

SAMPAIO, Vilomar Sandes; SAMPAIO, Andrecksa Viana Oliveira; ROCHA, Gabriela Silveira. Vitória da Conquista e a produção de biscoitos caseiros: as relações de 


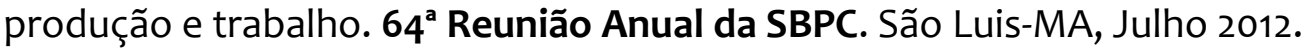
Disponível em: http://portal.sbpcnet.org.br/publicacoes/tipo/reunioes-anuais/. Acesso em: 26 Set. 2018.

SEBRAE - SERVIÇO BRASILEIRO DE APOIO ÀS MICRO E PEQUENAS EMPRESAS. Biscoitos caseiros/não industrializados. Estudos de Mercado SEBRAE/ESPM, 2008. . Sebrae apresenta projeto para dar mais visibilidade à produção de biscoito caseiro. Agência Sebrae de Notícias, Julho de 2018.

\section{. Diagnóstico de Potencial para Indicação Geográfica "Vitória da}

Conquista" para Biscoitos. UNIDADE REGIONAL 10 - Vitória da Conquista - Bahia, Março de 2019.

SCHNEIDER, Michele Domingos; ZILLI, Julio Cesar; PINTO VIERA, Adriana Carvalho. Os Impactos da Indicação de Procedência no Desenvolvimento Econômico na Produção de Uva, nos Municípios dos Vales da Uva Goethe - SC. Caderno de Prospecção, Salvador, v. 10, n. 2, p. 327-340, 2017.

DOI: http://dx.doi.org/10.9771/cp.v10i2.17928

SEI - SUPERINTENDÊNCIA DE ESTUDOS ECONÔMICOS E SOCIAIS DA BAHIA, 2017. Informações Municipais. Disponível em

https://www.sei.ba.gov.br/index.php?option=com_wrapper\&view=wrapper\&ltemid =266; Acesso 15 set. 2019 .

VANDECANDELAERE, Emilie; ARFINI, Filippo; BELLETTI, Giovanni; MARESCOTTI, Andrea. Uniendo personas, territorios y productos. Guía para fomentar la calidad vinculada al origen y las indicaciones geográficas sostenibles. 2010. Disponível em: http://www.fao.org/3/a-i1760s.pdf. Acesso em: 06 Fev. 2020.

VITÓRIA DA CONQUISTA. Lei n 2.320, de 29 de Agosto de 2019. Dispõe sobre a instituição no Calendário de Eventos do Município de Vitória da Conquista da "Semana do Biscoito" e dá outras providências. Vitória da Conquista: Câmara Municipal, [2019]. Disponível em:

http://arquivos.camaravc.com.br/legislacao/Lei_2019_2320_6593_\%28Leis_2019_232 0\%29.pdf. Acesso em: 06 Fev. 2020.

WILKINSON, John; CERDAN, Claire; DORIGON, Clovis. Geographical Indications and "Origin" Products in Brazil - The Interplay of Institutions and Networks. World Development, v. 98, pp. 82-92, 2017.

DOI: https://doi.org/10.1016/j.worlddev.2015.05.003 
Marta Aparecida Rodrigues de Oliveira. Mestre em Propriedade Intelectual e Transferência de Tecnologia para Inovação (PROFNIT) - IFBA. Graduada em Urbanismo pela Universidade do Estado da Bahia. Instituto Federal da Bahia IFBA. Tecnóloga em Gestão do IFBA.

Endereço: Rua Emídio dos Santos, s/n - Barbalho, Salvador - BA, 40301-015, IFBA Campus Salvador. Email: mrodriveira@gmail.com

Núbia Moura Ribeiro. Doutora e Mestre em Química pela Universidade Federal do Rio de Janeiro -UFRJ. Instituto Federal da Bahia - IFBA. Professora Permanente de Doutorado em Difusão de Conhecimento (IFBA, LNCC, SENAICIMATEC, UEFS, UNEB e UFBA) e Mestrado em Propriedade Intelectual e Transferência de Tecnologia para Inovação - PROFNIT (IFBA). Endereço: Rua Emídio dos Santos, s/n - Barbalho, Salvador - BA, 40301-015, IFBA - Campus Salvador. Email: nubiamr.ifba@gmail.com

Marcelo Santana Silva. Pós-Doutor pelo Programa de Pós-Graduação em Engenharia Industrial - PEI (UFBA). Doutor em Energia e Ambiente (UFBA), Mestre em Regulação da Indústria de Energia (UNIFACS). Instituto Federal da Bahia (IFBA). Docente Permanente do Mestrado em Propriedade Intelectual e Transferência de Tecnologia para a Inovação - PROFNIT (IFBA). Endereço: Rua Emídio dos Santos, s/n - Barbalho, Salvador - BA, 40301-015, IFBA - Campus Salvador. Email: profmarceloifba@gmail.com

Como citar: RIBEIRO, Núbia Moura; DE OLIVEIRA, Marta Aparecida Rodrigues; SILVA, Marcelo Santana. Oportunidades e Entraves Para a Proteção por Indicação de Procedência para os Biscoitos Artesanais de Vitória da Conquista-BA. Redes (St. Cruz Sul, Online), Santa Cruz do Sul, v. 25, p. 2592-2615, 2020. ISSN 1982-6745. doi:https://doi.org/10.17058/redes.v25i0.15115.

\section{CONTRIBUIÇÃO DE CADA AUTOR}

a. Fundamentação teórico-conceitual e problematização: Marta, Nubia, Marcelo

b. Pesquisa de dados e análise estatística: Marta e Nubia

c. Elaboração de figuras e tabelas: Marta e Marcelo

d. Fotos:

e. Elaboração e redação do texto: Marta, Nubia, Marcelo

f. Seleção das referências bibliográficas: Marta, Nubia, Marcelo

Fontes de financiamento: Não se aplica 